\title{
Quality of care delivered to type 2 diabetes mellitus patients in public and private sector facilities in Johannesburg, South Africa
}

This article was published in the following Dove Press journal: International Journal of General Medicine

\author{
Yacob Pinchevsky' \\ Frederick Raal ${ }^{2}$ \\ Neil Butkow' \\ Tobias Chirwa ${ }^{3}$ \\ Larry Distiller ${ }^{4}$ \\ Alan Rothberg 5 \\ 'Department of Pharmacy \\ and Pharmacology, School of \\ Therapeutic Sciences, Faculty of \\ Health Sciences, University of the \\ Witwatersrand, Johannesburg, South \\ Africa; ${ }^{2}$ Carbohydrate and Lipid \\ Metabolism Research Unit, Faculty \\ of Health Sciences, University of the \\ Witwatersrand, Johannesburg, South \\ Africa; ${ }^{3}$ Division of Epidemiology and \\ Biostatistics, School of Public Health, \\ Faculty of Health Sciences, University \\ of the Witwatersrand, Johannesburg, \\ South Africa; ${ }^{4}$ Centre for Diabetes \\ and Endocrinology, Johannesburg, \\ South Africa; ${ }^{5}$ School of Therapeutic \\ Sciences, Faculty of Health Sciences, \\ University of the Witwatersrand, \\ Johannesburg, South Africa
}

Purpose: With the realities of resource constraints existing in South Africa's public sector and the evidence of disparities in health care between populations, the study sought to compare the quality of diabetes care and health-related quality of life (HRQoL) in patients with type 2 diabetes mellitus (T2DM) receiving care within two specialized settings: one in the public and the other in the private sector. Particular emphasis was placed on complication rates at the two sites. Patients and methods: Quantitative and qualitative data were collected between June and October 2016 from existing patients' records at each setting. Data included patient demographics, potential barriers to accessing care, medical history, laboratory results, pharmacological treatment and diabetes-related clinical, biochemical and HRQoL outcomes. With outcome measurements being the priority, methodology incorporated the Donabedian model in which "structure" of health care systems, access to care and processes of care are key to determine outcomes.

Results: A total of 290 T2DM patients were enrolled. Analysis revealed that private patients were predominantly Caucasian with higher socioeconomic indicators $(p<0.01)$ and education levels $(p<0.0001)$ and experienced fewer access barriers to clinical services/care $(p<0.00001)$. Private patients also had more frequent consultations with dietitians $(p<0.0001)$, podiatrists $(p<0.0001)$ and biokineticists $(p<0.0001)$. In the important area of complications, which ultimately determine the course of T2DM, rates of micro- and macrovascular disease as well as HRQoL scores and sub-scores were similar between the sites, which were measured by the EuroQoL-5 dimension (EQ-5D) assessment tool. While results indicated that public sector care may be equivalent in terms of the latter outcomes, a smaller number of patients are treated in the clinic than would be ideal in terms of the public sector burden of T2DM.

Conclusion: Contrary to expectation, despite differences in patient demographics and resources, the HRQoL and quality of care, particularly in terms of T2DM-related complications, were found to be similar across the two settings.

Keywords: diabetes mellitus, quality, barriers, health-related quality of life

\section{Introduction}

Diabetes mellitus (DM) is a chronic progressive condition which results in significant morbidity, premature death and economic burden to any health care system. ${ }^{1}$ Globally, as many as 5.0 million people aged between 20 and 79 years died from diabetes-related conditions in 2015. This is equivalent to one person dying every 6 seconds. ${ }^{1}$ This makes DM more lethal than the combined number of deaths from HIV/AIDS (1.5 million), tuberculosis ( 1.5 million), and malaria ( 0.6 million) each year, with almost half $(46.6 \%)$ of the deaths occurring before 60 years of age. ${ }^{1}$ Due to the chronic nature of this disease, there is a need for regular provider visits, monitoring, management,
Correspondence: Yacob Pinchevsky Department of Pharmacy and

Pharmacology, School of Therapeutic Sciences, Faculty of Health Sciences, University of the Witwatersrand, 7 York Road, Parktown, Johannesburg 2193,

South Africa

Tel +27828374082

Fax +27 II 0264700

Email jpinchevsky@gmail.com 
medication supply and modification of treatment plans. Yet, despite the potential benefits of the available treatments, a wide gap still exists between actual and desired practices. Hence, patients with DM become exposed to increased risk of the micro- and/or macrovascular complications typically associated with the condition..$^{2-4}$ Unfortunately, many patients fail to receive the services they require due to barriers to health care and/or underperforming health care systems. Barriers may be patient related (eg, socioeconomic status, education, access to employment and private transportation) or health care system related (eg, infrequent health-related consultations/laboratory testing, long patient waiting times and limited drug formularies). ${ }^{5-9}$ As a consequence, patients with DM who are reliant on a functioning health care system may experience adverse health outcomes. Using the Donabedian model, ${ }^{10}$ this study set out to measure and compare the quality of diabetes care and health-related quality of life (HRQoL) associated with type 2 DM (T2DM) management in two specialized clinics within Johannesburg, South Africa.

\section{Patients and methods}

\section{Provider, patient and clinical} characteristics

The two sites chosen for this study were the public sector, Charlotte Maxeke Johannesburg Academic Hospital (CMJAH), and the private Centre for Diabetes and Endocrinology (CDE). The sites are close to one other $(2.48 \mathrm{~km})$ within adjacent and affluent suburbs of Johannesburg, but show differences in resource availability (Table 1). Both the CMJAH and CDE offer diabetes management by specialist and subspecialist physicians (ie, endocrinologists) who utilize evidence-based guidelines as their framework in the management of patients with T2DM. ${ }^{4}$

The CMJAH is a 1088-bed level 3 academic hospital offering in- and outpatient services to patients requiring medical, surgical, pediatric, obstetric and gynecological and psychiatric care. Through its association with the University of the Witwatersrand, the CMJAH is an academic hospital with facilities that cater for patient care, teaching and research and training of medical and allied under- and postgraduate students. Patients receiving diabetes care at the CMJAH are managed using guideline-derived clinical protocols. As with all public sector facilities in South Africa, medications prescribed to patients at the CMJAH are based on the national essential drug list (EDL) and purchased via the state tender system that acquires medication from manufacturers at substantially lower cost than the profit-driven private sector.
The CDE came into existence in 1994 as the first dedicated diabetes center of excellence in South Africa. Created by endocrinologists, the idea behind the CDE was to offer specialized care through a multidisciplinary program and team that also included diabetes nurse educators, podiatrists, dietitians and biokineticists. Over time, private health care insurers began contracting with the CDE program, which then became available to patients with private insurance (membership of a "medical scheme") throughout the country's "franchised" network of collaborating accredited CDE centers. However, in this study, the focus is on the CDE in Houghton, which is considered the "head office" of CDE as well as the center with the most advanced and comprehensive facilities. Characteristics of the two sites are detailed in Table 1. Patients at the CDE generally have access to a wider selection of drugs than are available to patients within the public sector, but this in turn may depend on a formulary determined by the patient's private medical scheme which might have a disease management program for associated conditions such as hypertension, hyperlipidemia, coronary artery and/or renal disease.

\section{Patient eligibility}

Patients were enrolled at the time of a clinic visit to CMJAH or CDE between June and October 2016. Only patients aged 18 years and older with a documented diagnosis of T2DM treated at either the CMJAH/CDE for at least 1 year were included in the study. For the purposes of this study, T2DM was defined as per the 2012 Society for Endocrinology, Metabolism and Diabetes of South Africa (SEMDSA) guidelines that applied at the time. ${ }^{4}$ Patients excluded were those with any other form of diabetes (eg, type 1 diabetes, gestational diabetes and steroid-induced diabetes) and women who were pregnant or breast feeding. Participants were consecutively chosen from the list of scheduled appointments provided by the administration office at the two study sites.

\section{Sample size}

The measurement most commonly utilized in the outcome studies of patients who have T2DM is HbA1c. Therefore, the percentages of patients achieving HbAlc targets $(<7 \%)$ from two published studies relevant to the population(s) under review were utilized to calculate the sample size needed $(50 \%$ for $\mathrm{CDE}$ and $25 \%$ for CMJAH). ${ }^{11,12}$ The confidence level selected was $95 \%$ (significance level of $5 \%$ ), and a power of $80 \%$ was chosen. Although the total sample size needed for the study was 188 patients ( 94 per site), a decision was taken to enroll $\pm 50 \%$ more, ie, \pm 150 patients from each site to allow 
Table I Characteristics of the CMJAH and CDE

\begin{tabular}{|c|c|c|}
\hline Clinical characteristics & CMJAH & CDE \\
\hline \multicolumn{3}{|l|}{ Patients } \\
\hline Reminders to attend clinics & No & Yes \\
\hline Regular communication on disease management & No & Yes \\
\hline Diabetic camps/meetings & No & Yes \\
\hline Additional case management if the disease is complicated & Yes & Yes \\
\hline \multicolumn{3}{|l|}{ Providers } \\
\hline Clinics per week & 2 days/week & 5 days/week \\
\hline Annual doctor consultations & \pm 200 per week & \pm 400 per week \\
\hline \multirow[t]{7}{*}{ Staff by discipline at the clinic } & Two endocrinologists & Six endocrinologists \\
\hline & Two generalist physicians & Two generalist physicians \\
\hline & Four medical officers ${ }^{\mathrm{a}}$ & Six nurse educators \\
\hline & Four nurse educators & Three dietitians \\
\hline & Two dietitians & Two podiatrists \\
\hline & Two podiatrists & Five biokineticists \\
\hline & & One clinical psychologist \\
\hline Continuing medical education offered to staff & Doctors only & $\begin{array}{l}\text { Doctors, nurse educators, } \\
\text { dietitians, podiatrists }\end{array}$ \\
\hline \multicolumn{3}{|l|}{ Facilities } \\
\hline Structured referral system of patients & No & Yes \\
\hline Incentives for staff to achieve certain targets & No & No \\
\hline Electronic patient management system & No & Yes \\
\hline Management care maps/protocols/guidelines & Yes & Yes \\
\hline Checklists of tests, visits, examinations, eg, biochemical, eyes and feet & Yes & Yes \\
\hline Formulary for the management of diabetes & Yes $(E D L)^{b}$ & Individualized ${ }^{c}$ \\
\hline Formulary for the management of hypertension & Yes (EDL) ${ }^{b}$ & Individualized ${ }^{c}$ \\
\hline Formulary for the management of hyperlipidemia & Yes $(E D L)^{b}$ & Individualizedc \\
\hline 24-hour emergency line & No & Yes \\
\hline
\end{tabular}

Notes: aMedical officer refers to a medical practitioner completing mandatory community service. 'EDL was developed by the National Department of Health for use in the public sector. 'The CDE is not limited by any formulary and therefore follows "individualized best practice" although is subject to the patient's private insurance cover (medical aid formulary).

Abbreviations: CDE, Centre for Diabetes and Endocrinology; CMJAH, Charlotte Maxeke Johannesburg Academic Hospital; EDL, essential drug list.

for dropouts and missing data and to enhance accuracy and validity of the results.

\section{Data collection (demographics)}

To explore differences in the quality of care between the two sites, Donabedian's framework (defined as the relationship between a health care system's structure, processes and outcomes) was adapted for the needs of this study. ${ }^{10}$ Patients were approached in the waiting area and provided with an overview of the study using a patient information sheet. If willing to participate, a voluntary consent form was signed, providing permission for both the interview process and access to clinical records. Patient demographics, medical history, most recent laboratory results, pharmacological treatment, and diabetes-related clinical and biochemical data were captured from each participant's clinical record. The data from both the interview questionnaire and clinical record were later transferred to a secure electronic database at the University of the Witwatersrand, Faculty of Health
Sciences, for safekeeping and analysis. Prior to the study, the University of Witwatersrand's Human Research Ethics Committee (HREC) granted ethical approval for the study (certificate no. M150140).

\section{Data collection (access issues)}

The interview included questions related to potential barriers to care experienced by study participants. In terms of the barriers that may have obstructed access to the necessary care from either the CMJAH or CDE, participants were asked if they were South African citizens/residents, were members of a medical scheme, the form of transportation (public/private) used, and the time it normally took to travel to the CMJAH/CDE. Purchasing of additional diabetes-related treatment (eg, medication) or services (laboratory tests, consultations and consumables such as glucometers and glucose test strips) outside of the participant's regular clinic (CMJAH/CDE) was also assessed. Further barriers such as personal, work or financial constraints or access to services/staff at CMJAH/CDE were also evaluated. 


\section{Data collection (processes of care)}

The processes of care for this study were derived from guidelines-CDE's "Minimum Care Guidelines" which were in fact based on the International Diabetes Federation (IDF) guidelines as well as the SEMDSA 2012 Diabetes Guidelines. ${ }^{1,4}$ These guidelines were also used as a means to benchmark performance across the study sites. The specific process measures that were captured from patients' records included the frequency of consultations each patient received from health care professionals (doctors, nurses, dietitians, podiatrists, ophthalmologists, optometrists, biokineticists) for a period of 12 months and the frequency of $\mathrm{HbAlc}$ and renal function tests performed for each patient. Glucose control was also assessed in terms of dietary and pharmacological management.

\section{Measurements of quality of care (Donabedian outcomes)}

A validated quality-of-life tool (EuroQoL-5 dimension [EQ5D]) was utilized to assess one of the primary outcomes of the study - HRQoL. ${ }^{13}$ The EQ-5D is a multi-attribute utility instrument (MAUI) which assesses health care problems on five levels and five dimensions of health (mobility, self-care, usual activities, pain/discomfort and anxiety/depression). Levels within each dimension from 1 to 5 are as follows: no problems, slight problems, moderate problems, severe problems and unable to perform the function. The dimension scores are converted into an overall HRQoL score for each subject, and individual scores are combined into a mean score for each site. The developers of EuroQoL in consultation with the researchers advised that the default UK dataset is used when calculating the outcomes from the data collected. Permission from the EuroQoL group was obtained prior to the EQ-5D tool being utilized for this study.

Microvascular disease included any of the following conditions: retinopathy (including blindness), neuropathy (including amputation) and nephropathy (including chronic kidney disease, chronic renal disease and chronic renal failure). Macrovascular disease consisted of cardiovascular and/ or cerebrovascular disease or equivalent (angina, myocardial infarction, ischemic heart disease, coronary artery disease, peripheral vascular disease, stroke, transient ischemic attack) and also cardiovascular-related procedures (stent, coronary artery bypass grafts).

The attainment of diabetes treatment goals for HbAlc using national guidelines (SEMDSA 2012) was compared for each setting. The achievement of target of $\mathrm{HbA} 1 \mathrm{c}<7 \%$ was ascertained from clinical records.

\section{Statistical analysis}

Following a 5-month data collection period, descriptive analysis was carried out for age, duration of diabetes and weight of participants at each study site. Where appropriate, the Student's t-test, chi-square test and Mann-Whitney U test were applied to test the association with key outcomes by site. Tests were two tailed, and a significance level of 5\% was used for the analysis. Microsoft Office Excel 2010 (Microsoft Corporation, Redmond, WA, USA) was chosen as the software for the study's databases, while statistical analysis was conducted by using Statistica version 13.2 (TIBCO Software Inc., Palo Alto, CA, USA).

\section{Results}

\section{Demographics}

The study included 290 adults (144 patients from the CMJAH and 146 from the Houghton CDE) aged $\geq 18$ years with T2DM. As summarized in Table 2, at the CMJAH, patients were younger, predominantly Black African and female, with less formal education, and were more likely to be single and unemployed.

Table 2 Demographic differences between patients attending $\mathrm{CMJAH}$ vs Houghton $\mathrm{CDE}$

\begin{tabular}{|c|c|c|c|}
\hline Characteristics & СМJAH & CDE & $p$-values \\
\hline Age (years) & $58.6 \pm 10.9$ & $63.2 \pm 12.2$ & $<0.001$ \\
\hline Females, n (\%) & $95(66.0)$ & $68(46.6)$ & $<0.001$ \\
\hline Duration of diabetes, $\mathrm{n}(\%)$ & $12.4(8.3)$ & II.6 (7.6) & NS \\
\hline Weight (kg) & $88.7 \pm 21.1$ & $89.6 \pm 21.8$ & NS \\
\hline \multicolumn{4}{|l|}{ Ethnicity } \\
\hline Black African, n (\%) & $92(63.9)$ & $19(13.0)$ & $<0.0001$ \\
\hline Caucasian, n (\%) & $17(\mid 1.8)$ & $92(63.0)$ & $<0.0001$ \\
\hline Indian/Asian, n (\%) & $26(18.1)$ & $29(19.9)$ & NS \\
\hline Mixed ancestry, n (\%) & $9(6.3)$ & $6(4.1)$ & NS \\
\hline \multicolumn{4}{|l|}{ Education } \\
\hline None, n (\%) & $12(8.5)$ & $3(2.1)$ & $<0.05$ \\
\hline Primary, n (\%) & $29(20.4)$ & $2(1.4)$ & $<0.0001$ \\
\hline Secondary, n (\%) & 85 (59.9) & $56(38.6)$ & $<0.001$ \\
\hline Tertiary, n (\%) & $16(11.3)$ & $84(57.9)$ & $<0.001$ \\
\hline \multicolumn{4}{|l|}{ Marital status } \\
\hline Single, $n(\%)$ & $29(20.7)$ & $16(11.0)$ & $<0.05$ \\
\hline Married, n (\%) & $67(47.9)$ & $99(67.8)$ & $<0.0001$ \\
\hline Divorced, n (\%) & II (7.9) & $9(6.2)$ & NS \\
\hline Widowed, n (\%) & $33(23.6)$ & $22(15.1)$ & NS \\
\hline \multicolumn{4}{|l|}{ Employment status } \\
\hline Unemployed, n (\%) & $40(28.2)$ & $15(10.3)$ & $<0.001$ \\
\hline Employed, n (\%) & $56(39.4)$ & $79(54.1)$ & $<0.01$ \\
\hline Retired, n (\%) & $46(32.4)$ & $52(35.6)$ & NS \\
\hline
\end{tabular}

Abbreviations: CDE, Centre for Diabetes and Endocrinology; CMJAH, Charlotte Maxeke Johannesburg Academic Hospital; NS, nonsignificant. 


\section{Access issues}

Since the lack of a South African identification document of citizenship or permanent residence is reported by some as being a barrier to access to clinical services (particularly in the public sector), it is important to record possession of such a document. As summarized in Table 3, almost all patients attending the two sites had such documentation (95.8\% CMJAH vs 97.9\% CDE). The table also summarizes that CMJAH patients made greater use of public transport and few were members of a private medical aid scheme. In terms of perceived access barriers such as financial difficulties, poor service delivery and personal issues, significantly more barriers were experienced by CMJAH patients than by patients attending CDE: $1.0(0-9)$ vs $0(0-5), p<0.00001$.

\section{Processes of care}

Table 4 summarizes the recorded frequency of consultations and tests for patients attending CMJAH and CDE. Patients

Table 3 Access differences between patients attending CMJAH vs Houghton CDE

\begin{tabular}{|c|c|c|c|}
\hline Characteristics & CMJAH & CDE & $p$-values \\
\hline \multicolumn{4}{|l|}{ Citizenship/residence } \\
\hline Identification, n (\%) & $138(95.8)$ & $143(97.9)$ & NS \\
\hline \multicolumn{4}{|l|}{ Transportation } \\
\hline Public, n (\%) & $88(62.4)$ & $\mathrm{I}(0.7)$ & $<0.000$ I \\
\hline Private, n (\%) & $53(37.6)$ & $145(99.3)$ & $<0.0001$ \\
\hline \multicolumn{4}{|l|}{ Travel time } \\
\hline$<30$ minutes, $\mathrm{n}(\%)$ & $49(34.3)$ & $92(66.2)$ & $<0.000$ I \\
\hline$>30$ minutes, $n(\%)$ & $94(65.7)$ & $47(33.8)$ & $<0.0001$ \\
\hline \multicolumn{4}{|l|}{ Medical aid } \\
\hline Medical insurance, n (\%) & $9(6.3)$ & 145 (99.3) & $<0.0001$ \\
\hline Patient-reported access barriers & $1.0(0-9)$ & $0(0-5)$ & $<0.00001$ \\
\hline
\end{tabular}

Abbreviations: $\mathrm{CDE}$, Centre for Diabetes and Endocrinology; CMJAH, Charlotte Maxeke Johannesburg Academic Hospital; NS, nonsignificant.

Table 4 Differences in frequency of annual health care professional visits and annual tests performed in study patients attending $\mathrm{CMJAH}$ vs Houghton $\mathrm{CDE}$

\begin{tabular}{llll}
\hline Characteristics & CMJAH & CDE & p-values \\
\hline Health care professional visits & & \\
$\quad$ Doctor & $3.2 \pm \mathrm{I} .2$ & $2.9 \pm \mathrm{I} .7$ & $\mathrm{NS}$ \\
Nurse & $3.0 \pm \mathrm{I} .4$ & $0.6 \pm \mathrm{I} . \mathrm{I}$ & $<0.000 \mathrm{I}$ \\
Dietitian & $0.2 \pm 0.6$ & $\mathrm{I} .2 \pm \mathrm{I} .4$ & $<0.000 \mathrm{I}$ \\
Podiatrist & $0.2 \pm 0.7$ & $\mathrm{I} .2 \pm \mathrm{I} .6$ & $<0.000 \mathrm{I}$ \\
Ophthalmologist & $0.1 \pm 0.5$ & $0.1 \pm 0.4$ & $\mathrm{NS}$ \\
Optometrist & $0.3 \pm 0.8$ & $0.4 \pm 0.6$ & $\mathrm{NS}$ \\
$\quad$ Biokineticist & 0 & $0.5 \pm \mathrm{I} .4$ & $<0.000 \mathrm{I}$ \\
Annual tests & & & \\
HbAlc & $2.8 \pm \mathrm{I} .0$ & $2.4 \pm \mathrm{I} .0$ & $<0.0 \mathrm{I}$ \\
Renal & $\mathrm{I} .4 \pm 0.8$ & $\mathrm{I} .9 \pm \mathrm{I} . \mathrm{I}$ & $<0.00 \mathrm{I}$ \\
\hline
\end{tabular}

Abbreviations: CDE, Centre for Diabetes and Endocrinology; CMJAH, Charlotte Maxeke Johannesburg Academic Hospital; NS, nonsignificant. at the $\mathrm{CDE}$ enjoyed greater access to specialized care, while at the CMJAH nurses played a much greater role in patient management. $\mathrm{HbA1} \mathrm{c}$ was tested at CMJAH more frequently than at the $\mathrm{CDE}$, while renal function was followed more closely at CDE.

The glycemic interventions or agents prescribed for patients attending CMJAH and CDE are shown in Figure 1. No patients attending CMJAH were recorded as using dietary modification alone as a means of lowering $\mathrm{HbA} 1 \mathrm{c}$ compared to seven patients from CDE. A combination of insulin and oral hypoglycemic agents was used at both sites, although larger numbers of patients using this combination were seen at CMJAH. More use of biguanides was seen at CMJAH $(88.2 \%$ vs $70.5 \% ; p<0.001)$, while sulfonylureas were prescribed to a greater extent at $\operatorname{CDE}(29.5 \%$ vs $16.0 \% ; p<0.01)$. Figure 1 also shows that while the hypoglycemic intervention rates differ, the prescribing "profiles", ie, the "shapes of the curves", are similar. Target HbA1c of $<7 \%$ was achieved by $45.5 \%$ of patients at $\mathrm{CDE}$ vs $27.3 \%$ at $\mathrm{CMJAH}(p<0.01)$.

\section{Donabedian outcomes}

No statistically significant differences in major complication rates (ie, micro- or macrovascular disease) could be found between patients attending CMJAH and CDE (Table 5). Rates of strokes and/or transient ischemic attacks were low at both sites.

As shown in Figure 2, the results of the five HRQoL elements were virtually superimposed on one another, and the overall HRQoL scores were not statistically different between the two sites (CMJAH $0.75 \pm 0.22$ vs CDE $0.80 \pm 0.23$; nonsignificant [NS]).

\section{Discussion}

DM is a major health problem in South Africa and is one of the leading causes of morbidity and mortality. ${ }^{14}$ Health care systems are critical to a successful response to DM, yet most health care systems across sub-Saharan Africa are overwhelmed by both communicable and noncommunicable diseases and are therefore underprepared for the rapidly increasing burden of DM. ${ }^{15}$ In addition, most studies in subSaharan Africa have focused on the epidemiology rather than on exploring the broad-based health care systems needed for effective management of DM and its associated risk factors.

The data from the current study clearly demonstrate that the patients who attended the public sector (ie, CMJAH) were more disadvantaged and potentially at greater risk of T2DM-related morbidity and mortality than the CDE group in terms of demographics, barriers to accessing care and 


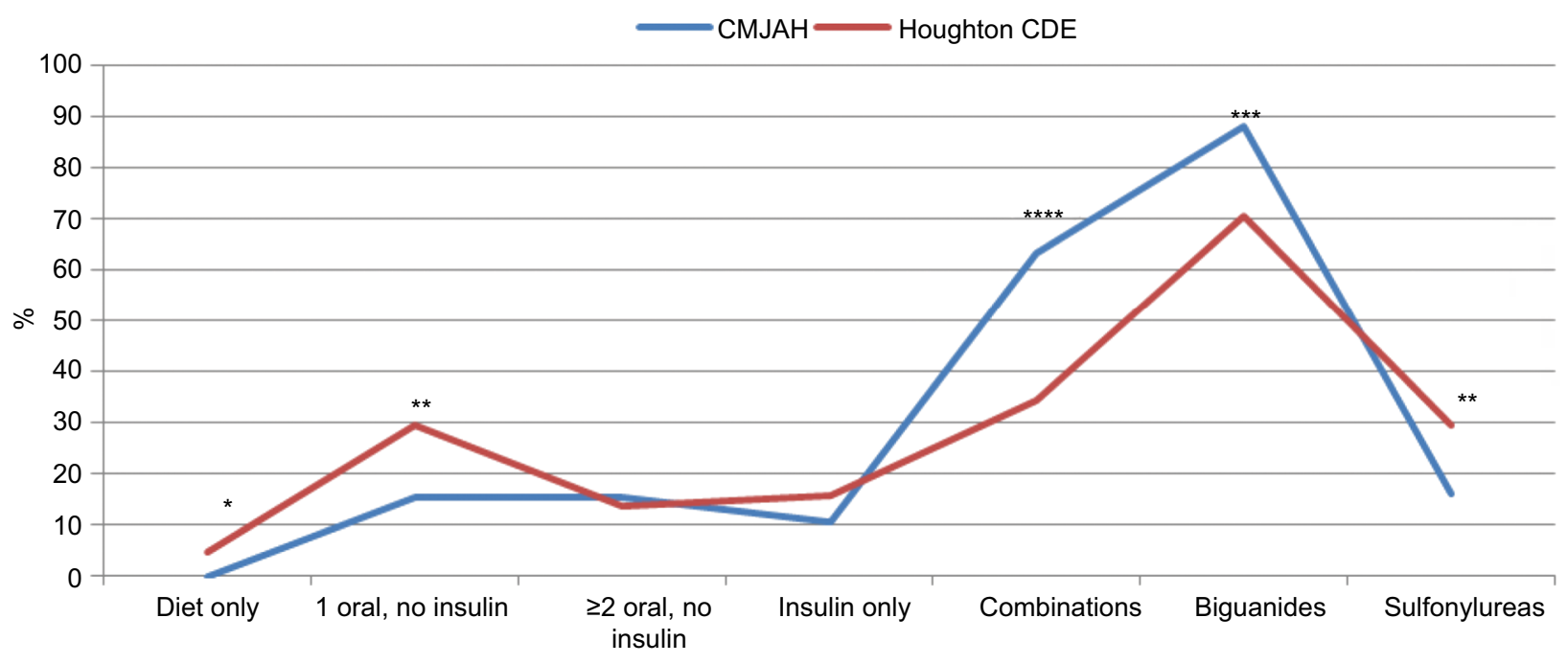

Figure I The percentage of patients using hypoglycemic medication at CMJAH vs Houghton CDE.

Note: ${ }^{*} p<0.05 ; * * p<0.001 ; * * * p<0.0001 ; * * * * p<0.00001$.

Abbreviations: CDE, Centre for Diabetes and Endocrinology; CMJAH, Charlotte Maxeke Johannesburg Academic Hospital.

Table 5 Complication rates in study patients attending $\mathrm{CMJAH}$ vs Houghton CDE

\begin{tabular}{llll}
\hline Characteristics & CMJAH & CDE & $\begin{array}{l}\boldsymbol{p} \text {-values } \\
\text { (pairs) }\end{array}$ \\
\hline $\begin{array}{l}\text { Complications } \\
\text { Cardiovascular disease, n (\%) }\end{array}$ & $23(16.0)$ & $23(15.8)$ & NS \\
Stroke or TIA, n (\%) & $4(2.8)$ & $3(2.1)$ & NS \\
Retinopathy, n (\%) & $20(13.9)$ & $27(18.5)$ & NS \\
Neuropathy, n (\%) & $17(11.8)$ & $26(17.8)$ & NS \\
Nephropathy, n (\%) & $14(9.7)$ & $13(8.9)$ & NS \\
\hline
\end{tabular}

Abbreviations: CDE, Centre for Diabetes and Endocrinology; CMJAH, Charlotte Maxeke Johannesburg Academic Hospital; NS, nonsignificant; TIA, transient ischemic attacks.

also to various processes of care. The CMJAH group showed evidence of more socioeconomic difficulties compared with CDE patients. This was noted by their lower levels of education and greater likelihood of being single and unemployed. In addition, the CMJAH patients suffered from limitations in accessing health care which could be attributed to being uninsured, more reliant on public transportation, traveling greater distances and experiencing various other perceived and real barriers. Furthermore, the CMJAH group did not have routine access to a full multidisciplinary team of health care professionals (eg, dietitians, podiatrists and biokineticists) and were restricted to an EDL of genericized medications which are often liable to substitution by the CMJAH dispensary. The CMJAH group was also shown to have fewer patients who reached the HbA1c target. Possible reasons for the latter difference are 1) the CDE "business model" and 2) logistic factors at CMJAH. The CDE contracts with private medical aid schemes, taking full risk for payments for the hospitalization of patients who suffer from hyper- or hypoglycemic crises. ${ }^{16}$ As such, the CDE has a direct interest in more aggressively managing $\mathrm{HbA} 1 \mathrm{c}$. It also emerged that $\mathrm{CDE}$ patients accessed additional services beyond the $\mathrm{CDE}$ for the monitoring of their blood sugar levels. In contrast, at the CMJAH, factors such as HbAlc levels only being available at the clinic visit subsequent to the one at which the blood sample was taken led to doctors having to treat on the basis of historical rather than current test results. The EDL-based formulary available at CMJAH and dispensary problems such as drug "stock outs" and changes in suppliers of the drugs may also have played a role. Nevertheless, the achievement of HbA1c targets at the two sites accords with data from the literature. ${ }^{17-19}$

With T2DM, it is the complications that are the key determinants and predictors of morbidity and mortality. ${ }^{1}$ In this study, while there were indeed differences in patients achieving $\mathrm{HbA1c}$ targets at the two sites, there were no statistically significant differences in major complication rates (ie, micro- and/or macrovascular disease) between patients at CMJAH and CDE. As summarized in Table 5, for macrovascular disease, these ranged from $2 \%$ to $3 \%$ for stroke/transient ischemic attacks and around $16 \%$ for cardiovascular disease. For microvascular disease, nephropathy rates were between $9 \%$ and $10 \%$, while neuropathy and retinopathy were somewhat higher $(12-14 \%$ at CMHAH vs around $18 \%$ at CDE). None of the inter-site differences were statistically significant, and all the complication rates were within the ranges identified in various South African studies, with most being toward the lower end of the ranges. ${ }^{17-19}$ 


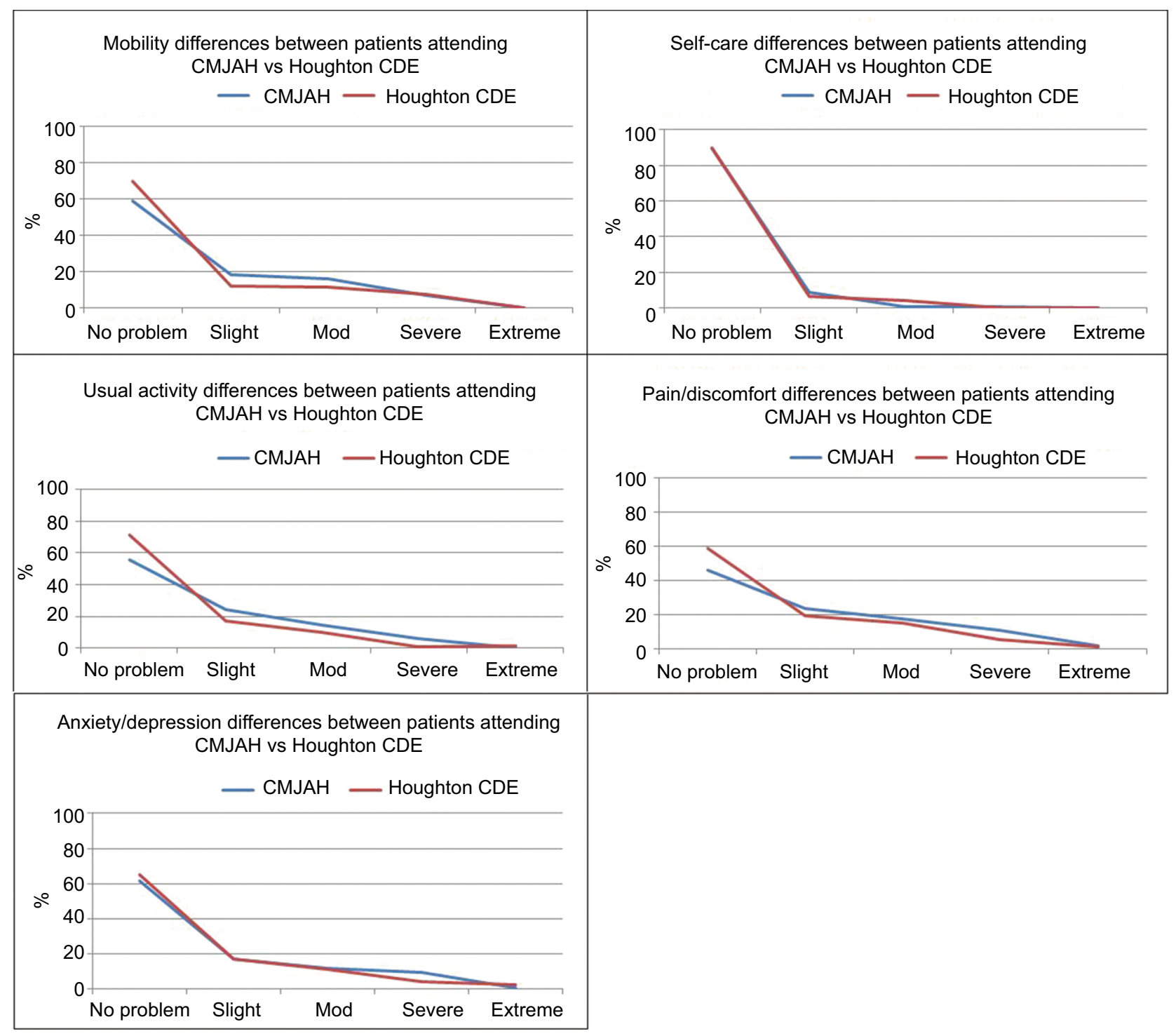

Figure 2 EuroQoL dimensions for patients attending CMJAH vs Houghton CDE.

Abbreviations: CDE, Centre for Diabetes and Endocrinology; CMJAH, Charlotte Maxeke Johannesburg Academic Hospital; Mod, moderate.

Whether patients with T2DM have or do not have complications, they may experience changes in lifestyle and reduced HRQoL. ${ }^{20,21}$ For example, the UK Prospective Diabetes Study (UKPDS) group directly assessed health utility scores in T2DM and found that subjects with microvascular complications had slightly lower scores than patients without complications or with macrovascular disease..$^{22}$ As shown in Figure 2, there were no differences in EQ-5D scores between the sites and no difference in the overall HRQoL scores. These HRQoL scores were generally in keeping with those from other DM studies. ${ }^{22}$ Thus, in terms of significant clinical complications and quality-of-life assessments at the two study sites, key Donabedian outcomes were found to be equivalent.
Although cross-sectional and observational in nature, this study provides information on the quality of diabetes care received in the two specialized health care settings. Nevertheless, some limitations should be noted. Only those patients who attended the study sites were included in the study. Hence, patients who might have missed their care/treatment at the sites for reasons such as disability through stroke or amputations were not included. In this regard, it can likely be assumed that CMJAH patients would have been more affected than CDE patients, eg, more barriers to accessing care for someone with a stroke or amputation. However, results showed that complications occurred at similar rates, and HRQoL score and sub-scores were similar. In other words, if there were indeed barriers to 
care, they were experienced at similar rates at the two sites. Clinical assessment of ocular and retinal complications is more rigorous at $\mathrm{CDE}$ and as such there is the possibility of relative under-diagnosis at CMJAH, particularly of early disease. This has been flagged as a subject for future research. Sample size is always a concern in a study of this nature. Perhaps with a larger sample, some results would have differed. While the primary objective of the current study was to assess the quality of care in T2DM patients attending a public vs a private specialized care clinic, the results are limited to these two particular settings.

\section{Conclusion}

Contrary to expectation and also to other research ${ }^{23,24}$ that has shown differences in health outcomes in the private vs public sector or insured vs noninsured populations, in the current study, complication rates and HRQoL outcomes were found to be similar across the two study sites. However, each week, the private sector, $\mathrm{CDE}$, treats twice as many patients as the public sector, CMJAH. In contrast, the burden of T2DM in the public sector, which treats $83 \%$ of South Africans, is orders of magnitude higher than the burden in the population served by the private sector. Consequently, one may conclude that, while the specialized public sector facility is able to achieve outcomes that are similar to those served by the CDE, in effect the care is limited to a relatively select few.

\section{Disclosure}

The authors report no conflicts of interest in this work.

\section{References}

1. International Diabetes Federation. IDF Diabetes Atlas. Seventh ed. Brussels, Belgium: International Diabetes Federation; 2015.

2. The UK Prospective Diabetes Study (UKPDS) Group. Intensive blood-glucose control with sulphonylureas or insulin compared with conventional treatment and risk of complications in patients with type 2 diabetes (UKPDS 33). Lancet. 1998;352:837-853.

3. Holman RR, Paul SK, Bethel MA, Matthews DR, Neil HA. 10-Year follow-up of intensive glucose control in type 2 diabetes. N Engl J Med. 2008;359:1577-1589.

4. Amod A, Ascott-Evans BH, Berg GI, et al. The 2012 SEMDSA guideline for the management of type 2 diabetes. JEMDSA. 2012;17(1):S1-S95.

5. Hwang J, Shon C. Relationship between socioeconomic status and type 2 diabetes: results from Korea National Health and Nutrition Examination Survey (KNHANES) 2010-2012. BMJ Open. 2014;4(8):e005710.
6. Zagozdzon P, Zaborski L, Ejsmont J. Survival and cause-specific mortality among unemployed individuals in Poland during economic transition. J Public Health (Oxf). 2009;31(1):138-146.

7. Rask KJ, Williams MV, Parker RM, McNagny SE. Obstacles predicting lack of a regular provider and delays in seeking care for patients at an urban public hospital. JAMA. 1994;271(24):1931-1933.

8. Littenberg B, Strauss K, Maclean CD, Troy AR. The use of insulin declines as patients live farther from their source of care: results of a survey of adults with type 2 diabetes. BMC Public Health. 2006;6:198.

9. Oche M, Adamu H. Determinants of patient waiting time in the general outpatient department of a tertiary health institution in north Western Nigeria. Ann Med Health Sci Res. 2013;3(4):588-592.

10. Donabedian A. The quality of care: how can it be assessed? JAMA. 1997;121(11):1145.

11. Pinchevsky Y, Butkow N, Raal FJ, Chirwa T. The implementation of guidelines in a South African population with type 2 diabetes. JEMDSA. 2013;18(3):154-158.

12. Stark Casagrande S, Fradkin JE, Saydah SH, et al. The prevalence of meeting A1C, blood pressure, and LDL goals among people with diabetes, 1988-2010. Diabetes Care. 2013;36(8):2271-2279.

13. EuroQol Group. EuroQol - a new facility for the measurement of health-related quality of life. Health Policy. 1990;16(3):199-208.

14. Bradshaw D, Groenewald $P$, Laubscher R, et al. Initial burden of disease estimates for South Africa, 2000. S Afr Med J. 2003;93(9):682-688.

15. Atun R, Davies JI, Gale EA, et al. Diabetes in sub-Saharan Africa: from clinical care to health policy. Lancet Diabetes Endocrinol. 2017;5(8): 622-667.

16. Distiller LA, Brown MA, Joffe BI, Kramer BD. Striving for the impossible dream: a community-based multi-practice collaborative model of diabetes management. Diabet Med. 2010;27(2):197-202.

17. Webb EM, Rheeder P, van Zyl DG. Diabetes care and complications in primary care in the Tshwane district of South Africa. Prim Care Diabetes. 2015;9(2):147-154.

18. Pillay S, Aldous C, Mahomed F. Diabetic patients served at a regional level hospital: what is their clinical picture? JEMDSA. 2015;20(1): 60-66.

19. Levitt NS, Zwarenstein MF, Bawa AA, Maphumolo S. Audit of public sector primary diabetes care in Cape Town, South Africa: high prevalence of complications, uncontrolled hyperglycaemia, and hypertension. Diabet Med. 1997;14:1073-1077.

20. Grandy S, Fox KM. EQ-5D visual analog scale and utility index values in individuals with diabetes and at risk for diabetes: findings from the Study to Help Improve Early evaluation and management of risk factors Leading to Diabetes (SHIELD). Health Qual Life Outcomes. 2008;6(1):18.

21. Holmes J, McGill S, Kind P, Bottomley J, Gillam S, Murphy M. Healthrelated quality of life in type 2 diabetes (TARDIS-2). Value Health. 2000;3(suppl 1):47-51.

22. Quality of life in type 2 diabetic patients is affected by complications but not by intensive policies to improve blood glucose or blood pressure control (UKPDS 37). U.K. Prospective Diabetes Study Group. Diabetes Care. 1999;22(7):1125-1136.

23. Dexheimer Neto FL, Rosa RG, Duso BA, et al. Public versus private healthcare systems following discharge from the ICU: a propensity scorematched comparison of outcomes. Biomed Res Int. 2016;2016:6568531.

24. Schoenfeld AJ, Jiang W, Harris MB, et al. Association between race and postoperative outcomes in a universally insured population versus patients in the State of California. Ann Surg. 2017;266(2):267-273.
International Journal of General Medicine

\section{Publish your work in this journal}

The International Journal of General Medicine is an international, peer-reviewed open-access journal that focuses on general and internal medicine, pathogenesis, epidemiology, diagnosis, monitoring and treatment protocols. The journal is characterized by the rapid reporting of reviews, original research and clinical studies across all disease areas.

\section{Dovepress}

The manuscript management system is completely online and includes a very quick and fair peer-review system, which is all easy to use. Visit $\mathrm{http}: / /$ www.dovepress.com/testimonials.php to read real quotes from published authors. 